Document downloaded from:

http://hdl.handle.net/10251/98651

This paper must be cited as:

Picazo-Rodenas, MJ.; J. Antonino-Daviu; Climente Alarcon, V.; Royo, R.; Mota-Villar, A. (2015). Combination of Noninvasive Approaches for General Assessment of Induction Motors. IEEE Transactions on Industry Applications. 51(3):2172-2180. doi:10.1109/TIA.2014.2382880

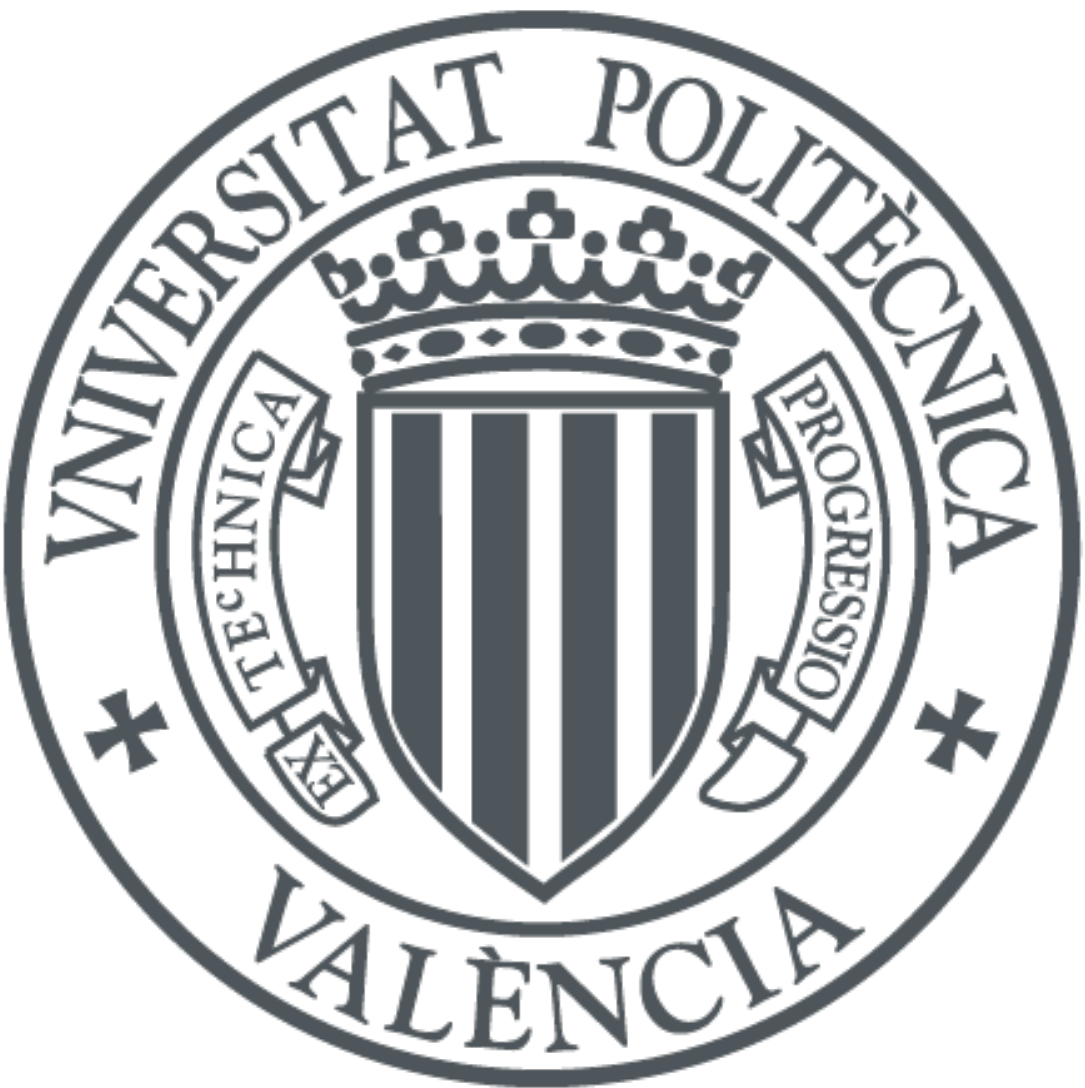

The final publication is available at

http://doi.org/10.1109/TIA.2014.2382880

Copyright Institute of Electrical and Electronics Engineers

Additional Information 


\title{
Combination of non-invasive approaches for general assessment of induction motors
}

\author{
M.J. Picazo-Ródenas, J. Antonino-Daviu, Senior Member, IEEE, V. Climente-Alarcón, Member, \\ IEEE, R. Royo-Pastor and A. Mota-Villar
}

\begin{abstract}
There exists no single quantity able to diagnose all possible failures taking place in induction motors. Currents and vibrations monitoring are rather common in the industry, but each of these quantities alone can only detect some specific failures. Moreover, even for the specific faults that a quantity is supposed to detect, many problems may rise. As a consequence, a reliable and general diagnosis system cannot rely on a single quantity. On the other hand, it would be desirable to rely on quantities that can be measured in a noninvasive way which is a crucial requirement in many industrial applications. This paper proposes a twofold method to detect electromechanical failures in induction motors. The method relies on analysis of currents (steady-state + transient) combined with analysis of infrared data captured by using appropriate cameras. Each of these non-invasive techniques may provide complementary information that may be very useful to diagnose an enough wide range of failures. In the present paper, the detection of three illustrative faults is analyzed: broken rotor bars, cooling system problems and bearing failures. The results show the potential of the methodology that may be especially suitable for large, expensive motors where the prevention of eventual failures justifies the costs of such system, due to the catastrophic implications that these unexpected faults may have.
\end{abstract}

Index Terms-- Induction machines; fault diagnosis; infrared analysis; rotor asymmetries; bearing faults.

\section{INTRODUCTION}

$\mathrm{F}$ AULT detection in induction motors has become a topic with increasing interest both in the academia and in industry [1]. Catastrophic effects in such energy conversion devices justify the importance of carrying out proper maintenance programs of those machines. Large induction motors are especially critical due to several reasons; they are very expensive machines, they are often crucial components in the industrial processes where they participate (so their eventual failure may imply high costs in terms of unplanned production shutdowns) and, finally, their repair and transportation costs are huge [2]. Over recent years, many researchers have developed techniques with the aim of detecting a wide range of faults in these motors, when these faults are still in their early stages. Most of these techniques often rely on a single quantity, since the authors pursue the simplicity and economy of their methods. In this context, currents [1, 3-5], vibrations [6-7], stray fluxes [7-8, 25-26], voltages [9], active and reactive powers $[10]$, etc... have been proposed as bases of the different diagnostic methodologies. However, in spite of the reliability of some of these approaches to detect certain specific faults, few of them has proven to be enough general

M.J. Picazo-Ródenas, J. Antonino-Daviu, R. Royo-Pastor and A. Mota-Villar are with Instituto de Ingeniería Energética, Universitat Politècnica de València, Camino de Vera s/n, 46022, Valencia SPAIN (emails: picazo_mar@gva.es, joanda@die.upv.es, rroyo@ter.upv.es).

V. Climente-Alarcón is with the Department of Electrical Engineering and Automation, Aalto University, P.O. Box 13000, 00076 Espoo, Finland (e-mail: viclial@ieee.org) to diagnose a wide range of failures with high reliability. Moreover, several methods based on some of the aforementioned quantities have an invasive nature, since they often imply the installation of sensors, probes, coils or auxiliary equipment, that requires to stop the machine or other interferences with its operation process; this is often unacceptable in many industrial applications.

Lately, current-based methods have gained prominence both in the literature of the area and in the industry. This is partially due to the fact that the stator current waveform can be registered in a non-invasive manner (a current clamp and an oscilloscope is often enough) and, also, the software that is needed for its processing is rather simple. In this regard, the classical method relying on current analysis, known as Motor Current Signature Analysis (MCSA)), is based on capturing the current demanded by the machine during steady-state operation and its subsequent analysis by using the Fast Fourier Transform (FFT); the idea is to identify, in the FFT spectrum, 'fault indicating frequencies', the amplitude of which has been amplified by the corresponding failure: the presence of these 'frequencies' is usually a reliable indicator of the existence of the fault.

This classical current-based method, however, has some important drawbacks that have been reported in the literature: difficulty when diagnosing some faults under certain operating conditions (pulsating load torques [11-12], unloaded machines [12], etc...) that may be rather common in the industry, unsuitability when detecting certain failures in specific machines (motors with rotor cooling axial ducts [13], double cage rotor motors [14], etc...), problems for fault discrimination... All these problems may have disastrous consequences, especially in large motors; as an example coming from an own industrial experience, MCSA was used to diagnose the condition of several large motors (powers of MW, unitary cost around 1,5 million \$) in a real industrial facility. One of these motors was diagnosed as faulty due to the presence in the FFT spectrum of some components with significant amplitudes at frequencies similar to fault-related ones; this motor was subsequently transported to the repair workshop and later disassembled. No fault was found; the false 'frequencies' were maybe due to the operation duty of the machine (presence of driven load fluctuations). These false positives, implied a cost around one third of the motor cost (leaving aside the production losses).

To overcome the problems of the classical MCSA method, several diagnosis strategies have been proposed over recent years. A quite recent alternative that has shown very good results is based on analyzing current signals by applying advanced signal processing tools [12, 15-16]. These approaches are able to process the current signal regardless of the machine regime (stationary or transient); their underlying idea is to track the evolutions of faultrelated frequency components over time (i.e. to detect a 
time-frequency evolution). The detection of such evolutions is a very reliable indicator of the presence of the failure. As an example, when the machine is connected (assuming that it is grid-supplied) the frequency of the Lower Sideband Harmonic associated with broken rotor bars, follows a very characteristic evolution over time, as the machine accelerates. This evolution, well characterized in previous works $[12,14]$, leads to a very characteristic pattern that can be used to diagnose the presence of the failure. The same happens with other fault-related harmonics that also lead to particular evolutions, the detection of which increases the reliability of the diagnostic. Moreover, other faults also lead to patterns that are different depending on the failure. The only constraint of this methodology is that, to obtain such patterns, advanced signal processing tools (Time-Frequency Decomposition (TFD) tools), able to process non-stationary quantities, must be used. In this context, several TFD tools have been proposed and are valid for the stated goals [16]: wavelet transforms, HilbertHuang transform (HHT), Wigner-Ville Distributions1) (WVD), Choi-Williams Distributions (CWD), etc...

This methodology has shown very good results for the diagnosis of some specific failures such as rotor failures or eccentricities. Moreover, it has been validated in motors ${ }^{2}$ ) with different sizes (from few $\mathrm{kW}$ till MW). However, despite the indubitable advantages of the new transient current-based methods, logically, they are not the panacea, ${ }^{3}$ i.e., they cannot provide a definitive diagnosis conclusion for every possible fault. There are some failures that, due to their inherent nature, are not easy to be detected by only using the analysis of the currents. This is the case, for instance, of bearing failures or insulation degradation. In this context, the use of other techniques is mandatory to build an enough general and reliable diagnostic system, able to detect a wide range of possible failures in the machine. In this paper, the infrared thermography technique is proposed as a complementary informational source for induction machine condition monitoring. The non-invasive characteristic of this technique makes it especially attractive. Moreover, its somehow complementary nature versus current analysis confers it with a potential that other quantities do not have. The cost increment provoked by the necessity of an infrared camera may be easily compensated by the advantage of a higher reliability, especially in large, critical motors.

The paper is structured as follows: in Section II, the proposed twofold approach is explained; on the one hand, a transient current-based diagnosis approach based on the HHT is presented and, on the other, the infrared-based complementary technique is also analyzed. Section III describes the experimental setup employed for the validation of the method. In Section IV, the results are shown and discussed. Finally, the conclusions of the work are synthesized in Section V.

\section{TWOLFOLD APPROACH}

\section{A. Currents analysis}

1) Traditional MCSA

MCSA has been extensively used in the industry for the diagnosis of certain failures. Based on the identification of particular 'fault indicating frequencies' in the FFT spectrum of the steady-state current, it has shown satisfactory results for the detection of rotor faults or eccentricities [1, 27]. Most of the commercial devices with current-monitoring features rely on this technique to assess the rotor condition. As it is well-known, in the event of broken rotor bars, two prominent peaks, known as sideband components (lower and upper) appear at both sides of the supply frequency. In the case of mixed eccentricities, other components appear. For instance, for an eccentric machine with two pole pairs, two 'fault indicating frequencies' rise at $f / 2$ and $3 \bullet f / 2 \mathrm{~Hz}$ ( $f$-supply frequency) [6].

MCSA has, however, some important drawbacks, some of them already stated in Section I. Most of these problems are related to the relatively frequent possibility of leading to wrong diagnostic conclusions, either false positives (diagnosing a healthy machine as faulty) or false negatives (diagnosing a faulty machine as healthy). These erroneous diagnostics have been reported in situations that may be rather common in industrial sites.

As an example, when assessing the rotor condition, false positives may be caused by the following situations:

1) Presence of load torque oscillations (motors driving compressors, pumps, gear reducers) may introduce in the FFT spectrum harmonics at frequencies rather similar to the fault-related ones, as proven in [11-12, 15, 28].

2) Cooling rotor axial ducts may introduce components similar to rotor fault-ones when the number of cooling ducts $\left(N_{d}\right)$ and machine poles $\left(N_{p}\right)$ are equal $[2,13]$.

3) Magnetic anisotropy issues may also lead to false positive indications as recently proven in [35].

On the other hand, false negatives may appear in the next cases:

1) Motors diagnosed in unloaded conditions: in this case, since the slip $s$ is low, the sideband components overlap the supply frequency becoming very difficult their identification $[12,15]$.

2) Detection of outer cage breakages in double cage rotors: in steady-state, the current flow is mostly confined in the inner cage, so an eventual bar breakage in the outer cage may not lead to significant harmonics in the FFT spectrum $[14,36]$.

3) Diagnosis of non-adjacent bar breakages; it is wellknown that, if the breakages take place in non-consecutive bars, for certain relative positions, their effects may even compensate leading to low amplitudes of the sideband harmonics and eventually to false negative indications [37].

\section{2) Advanced Harmonic Tracking Techniques}

To overcome the drawbacks of MCSA, alternative strategies have been proposed over recent years. One of the most successful approaches relies on not restricting the analysis to the stationary regime, but extending it to the transient regimes through which the machine operates. In other words, instead of only focusing on the steady-state current, the approach proposes the analysis of the current regardless of the operation regime of the machine (hence, including the analysis of transient current signals such as the current during the startup, sudden load variations, plug stopping, etc...) [15].

The problem in this case is that, if we want to analyze non-stationary quantities, the FFT is no longer suitable. The use of adequate signal processing tools suited for the analysis of such quantities becomes necessary. Is in this context where the Time-Frequency Decomposition (TFD) tools play a crucial role. These tools enable to obtain a time-frequency 'picture' of the analyzed signal. Hence, they allow the observation not only of the frequency components 
present in the signal but also of how they evolve over time. Indeed, it is precisely their ability to track the timefrequency evolution of fault-related components which confers them with a high reliability, since the patterns created by such evolutions are very difficult to be caused by other phenomena different from the failure (unlike what happens with the 'fault indicating frequencies' in the FFT spectrum). There are many possible TFD tools that are able to accomplish this function [16]: wavelet transforms (Continuous (CWT), Discrete (DWT), Undecimated (UDWT), Wavelet packets (WP), etc...), Hilbert-Huang Transforms (HHT), Wigner-Ville Distributions (WVD), Choi-Williams Distributions (CWD)... have been applied in previous literature to this end. As an example, Fig. 1 shows the Hilbert-Huang spectrum of the second intrinsic mode function (IMF2, that covers the frequency band below 50 $\mathrm{Hz}$ ) resulting from the application of the HHT to the startup current of a healthy machine (Fig. 1 (a)) and to a machine with two broken bars (Fig. 1 (b)). This spectrum is just a time-frequency representation of the analyzed current signal. It can be observed a V-shaped pattern caused by the evolution of a particular fault component, the lower sideband component (LSC), during this transient. Logically, this pattern does not appear for the healthy machine, since the fault component is absent.

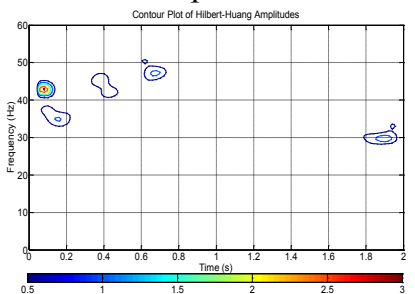

(a)

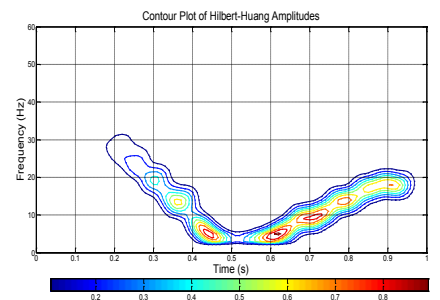

(b)
Fig. 1. Application of HHT (HH spectrum of IMF2) to the startup current of a: (a) healthy motor and (b) motor with two broken rotor bars

The qualitative identification of fault-related patterns must be accompanied by a quantitative perspective in order to determine the severity of the failure in the machine. In this regard, several quantification indicators have been proposed relying on different TFD tools. Most of the indicators are based on the computation of the energy in specific regions or 'boxes' of the time-frequency map that the faultcomponents trespass during their evolutions. Based on numerous tests performed with different motors and levels of failure, approximate intervals have been created, so that each one of these intervals is linked to a certain fault severity level. As an example, (1) gives the expression of a rotor asymmetry indicator based on the HHT [17], where $i_{j}$ is the value of the $j$ sample of the current signal; $\operatorname{imf} 2(j)$ is the $j$ element of the IMF2 signal covering the frequency range in which the LSC evolves during the startup transient; $N_{s}$ is the number of samples of the signal, until reaching the steady-state regime and $N_{b}$ is the number of samples between the origin of the signals and the extinction of the oscillations due to border effects.

$$
\gamma_{H H T}(d B)=10 \cdot \log \left[\frac{\sum_{j=N b}^{N s} i_{j}^{2}}{\sum_{j=N b}^{N s}[i m f 2(j)]^{2}}\right]
$$

This new diagnosis philosophy, relying on tracking the components linked to the failure and on the further computation of fault indicators has shown very satisfactory results for the diagnosis of certain failures (namely, rotor failures and eccentricities), both in small and in large $\mathrm{AC}$ motors, while avoiding false indications provided by MCSA $[2,12,15,17,36-37]$. However, the viability of the method is uncertain for the detection of some failures that are traditionally difficult to be detected via current analysis. This is the case of bearing faults or incipient stages of stator winding failure (e.g. turn-to-turn shorts [29-33], few broken turns in one phase...). For the detection of bearing failures, the information provided by other quantities such as vibrations or temperatures may be very useful to achieve a reliable conclusion. The use of vibrations has been also proposed for turn fault detection [34]. On the other hand, stray flux analysis has been revealed as a very reliable quantity to diagnose winding failures even when these are in their early stages [25, 29-33].

\section{B. Infrared data analysis}

The infrared thermography technique enables to visualize with high precision the superficial temperatures of a certain object in a non-invasive way, without necessity of any contact with the analyzed object. The underlying bases rely on converting infrared radiation measurements into temperature measurements. This is achieved by measuring the radiation emitted by the object surface within the infrared portion of the electromagnetic spectrum and by converting these measurements into electrical signals. The measurement device consists of an infrared camera, which measures the superficial temperature gradients by means of its infrared sensors, through the capture of high quality images.

The application of the infrared thermography technique to condition monitoring of electric motors is certainly limited. The few papers in the area (not only restricted to motors) have focused on the diagnosis of faults as: insulation failures in the magnetic circuit, deficient connections or misalignments [18]-[22]. However, most of the works aim to detect simple failures, often external to the machine. In addition, the interpretation of the resulting images is carried out in a very qualitative way, requiring the user expertness for the identification of the anomaly. In [22], groundwall insulation system is evaluated in medium voltage motors by using infrared thermography. On the other hand, [23] points out that infrared thermography is currently employed to monitor high resistance connections. Misalignment effects and their implications in thermography are studied in [21]. In concordance to these facts, the use of the infrared thermography for the study of the thermal behaviour of electric motors has neither been very abundant, despite some interesting results obtained in recent contributions [24].

Due to the recent technological development in the area of infrared cameras, new opportunities are presented for the use of such equipment in motor diagnostics: there are cameras, with affordable prices, that enable the capture of high resolution images so that the user can visualize with great precision the accurate temperatures in different points of the registered area. Most of these cameras make even the capture of thermal transients possible (nowadays, the minimum cost of a camera enabling thermal transient registration can be of $\sim \$ 10,000$ but the trend is that it will be even lower in the near future). These transients are represented by means of sequences of images that enable to obtain the temperature evolution in any point of the captured image, as well as to compute diverse statistic parameters related to the registered thermal map. Therefore, the application of the thermography to electric motors is far from being enough exploited. There is a wide area in which 
the application of this technique can provide very valuable information both for electric machine diagnosis and for behaviour analysis.

\section{Proposed twofold method}

The proposed approach relies on the joint use of current data and infrared thermography data. The method starts with the capture of the stator current signal (a single phase is enough) with a sampling rate enabling the visualization of all possible fault related components (as a reference, $5 \mathrm{kHz}$ is usually enough). With regards to the registered time interval, it determines the frequency resolution in the MCSA analysis but, also, the longer the interval the better the tracking of possible fault-related harmonics (it is more feasible to identify eventual fault harmonics and their evolutions). Usually 10 seconds is enough. Once the current signal has been captured, it is analyzed by using the conventional MCSA approach. MCSA diagnostic result is a good approximation to know the machine condition but it is not conclusive since it may lead, as commented, to eventual false positives or false negatives.

Hence, a subsequent analysis by using the advanced harmonic tracking techniques is necessary (regardless, of MCSA result), either to ratify the MCSA results or to discard them. If both techniques lead to the conclusion that the machine is faulty, it is very likely that the fault is present in the machine and no further analysis is, in principle, required. However, if their conclusions are different or even if both of them lead to the conclusion that the machine is healthy, further analysis of infrared data is advisable (in this latter case, it may happen that current analysis is not able to detect the fault). In these situations, analysis of infrared data may help to reach a diagnostic conclusion increasing the reliability of the diagnostic. Fig. 2 shows a schematic flowchart that illustrated the application process of the proposed twofold methodology.

\section{EXPERIMENTS}

The proposed twofold diagnosis method was validated in a laboratory three-phase, 4-pole, $1,1 \mathrm{~kW}$ induction motor. The rated characteristics of the motor are shown in Table I. In the experiments, the motor was driving a DC machine acting as a load. The variation of the excitation current of the DC machine enabled to easily test the induction motor at different load levels. In each test, the induction motor was started direct on-line, i.e., directly supplied from the grid. A waveform recording instrument (Yokogawa DL-850 Scopecorder) connected to a current probe enabled the registration of a phase stator current signal both during the startup and during steady-state. These current signals were later transferred to a PC for the analyses in MATLAB.

On the other hand, an infrared camera was used for recording the whole transient cooling process of the machine, till the steady-state regime was well reached. Images were captured at each second by using a highsensitivity long wave FLIR S65 Series camera, fitted with a firewire connection. The camera was connected with a portable computer, which was provided with an acquisition and analysis software, Thermacam Researcher. This software allows the visualization of the captured images, as well as knowing, with high accuracy, the temperature distribution on the frame of the motor at any time. The software program enables an accurate temperature measurement and computation of different statistical tools. Fig. 3 shows a picture of the experimental bench.

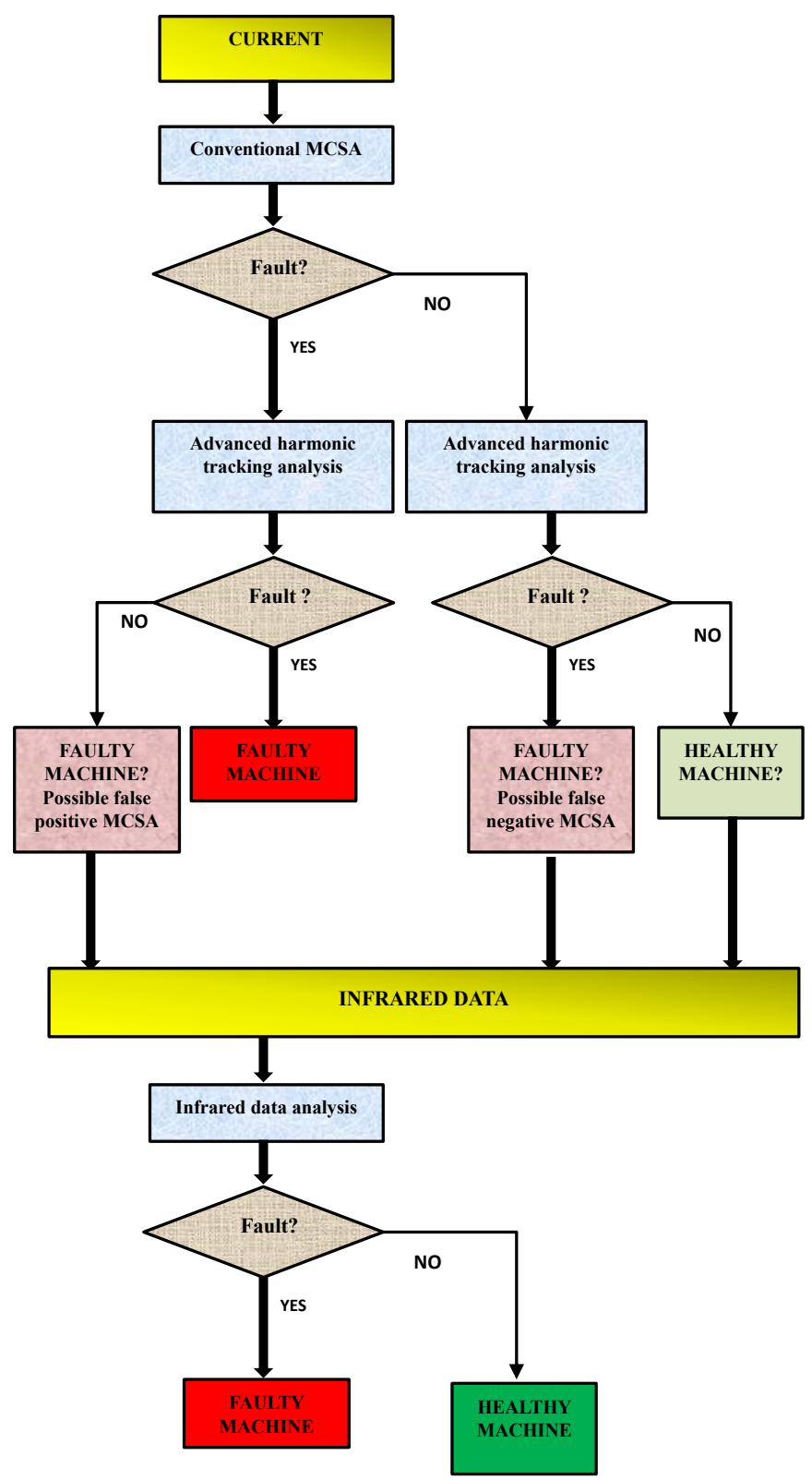

Fig. 2. Flowchart of the proposed twofold diagnosis approach

TABLE I

RATED CHARACTERISTICS OF THE TESTED MOTOR

\begin{tabular}{l|l}
\hline \multicolumn{2}{l}{ Model 1LA2080-4AA10 } \\
\hline Rated power $\left(\mathrm{P}_{\mathrm{N}}\right)$ & $1.1 \mathrm{~kW}$ \\
\hline Rated speed $\left(\mathrm{n}_{\mathrm{N}}\right)$ & $1410 \mathrm{rpm}$ \\
\hline Rated voltage $\left(\mathrm{U}_{\mathrm{N}}\right)$ & $400(\mathrm{Y}) / 230(\Delta)$ \\
\hline Rated current $\left(\mathrm{I}_{\mathrm{N}}\right)$ & $2.7(\mathrm{Y}) / 4.6(\Delta)$ \\
\hline Rated power factor $(\operatorname{Cos} \varphi)$ & 0.8 \\
\hline Number of rotor bars & 28 \\
\hline
\end{tabular}

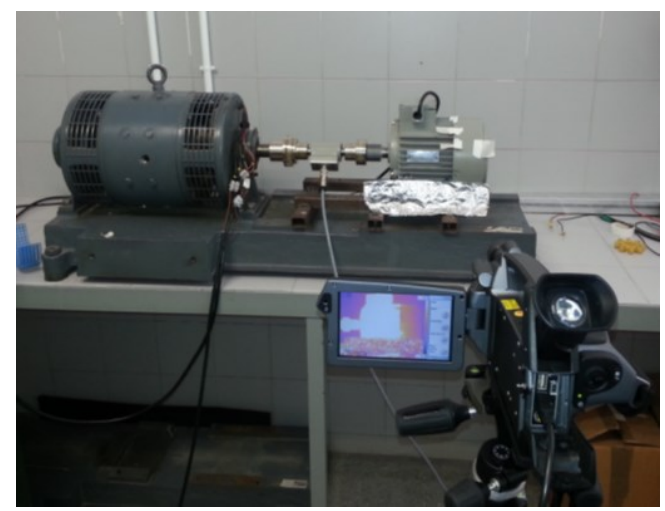

Fig.3. Experimental bench 


\section{RESULTS AND DISCUSSION}

\section{A. Rotor bar failures}

Rotor bar failures were forced by drilling a hole in the corresponding bars. Different faulty cases were tested (one, two and nine broken rotor bars) and under different load levels (from no-load till full load). In each case, once the faulty rotor was installed, the motor was line-started. Phase currents were registered by means of the waveform recorder. At the same time, infrared images were captured by using the camera described above.

Subsequent analyses of the results reveal that this is a (conventional MCSA + Advanced Harmonic Tracking Analysis). MCSA is a reliable technique for rotor assessment [2, 38]. However, as commented, it may have problems in some specific cases where the fault related components may not be discerned (e.g. no-load conditions [12-15], non-adjacent breakages [37], detection of broken outer bars in double cage rotors $[14,36])$ or may be confused with other similar frequencies (presence of load torque oscillations $[11-12,15,28]$, existence of cooling axial ducts [2, 13] or magnetic anisotropy issues [35]). The case of unloaded machine is illustrated in Fig. 4 that shows the FFT spectrum of the steady-state phase current of such machine. However, in these problematic cases the Advanced Harmonic Tracking Analysis is an excellent complement, since it enables to reliably detect the fault component signatures in the $t-f$ maps and, hence, to diagnose the presence of the failure. This is shown in Fig. 5 where the $\mathrm{HH}$ spectrum of the IMF2 for the no-load machine with two broken bars is plotted (an alternative color representation is adopted in that figure). The Vshaped pattern associated with the fault can be clearly observed there.

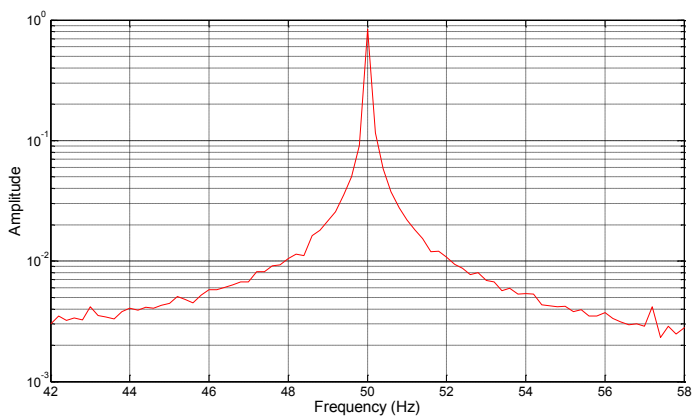

Fig. 4. MCSA analysis for the faulty machine under no-load (two broken bars)

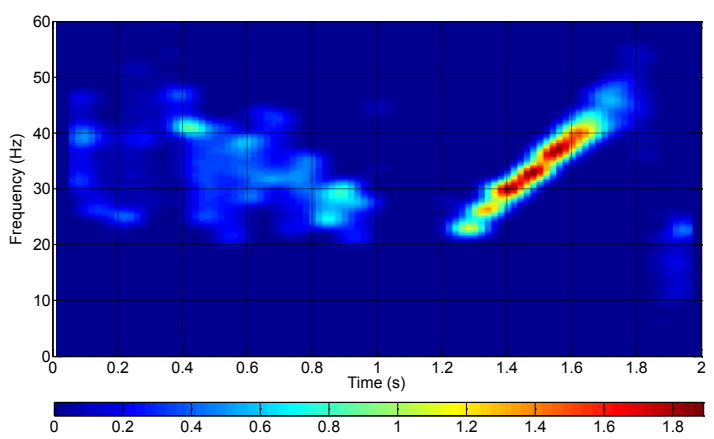

Fig. 5. HH spectrum of IMF2 of the startup current for a machine with two broken rotor bars under no-load

The application of the infrared technique for the detection of this specific fault does not lead to conclusive results. As shown in Fig. 6, the infrared images for the faulty machine reveal a general increase of the temperature in the motor frame. This increment, however, does not fit a specific pattern and could not be employed to reliably detect the failure since it may be caused by another abnormality or operation condition. Moreover, this increment is clearly noticeable only when a significant number of broken bars is present (as in Fig. 6). In any case, the general temperature increment detected in the infrared images somehow informs on the fact that the machine is not operating as it should do in healthy conditions. The absence of an accurate pattern is due to the fact that this is an internal fault. When the bar breaks, higher currents flow through the adjacent bars leading to temperature increments. However, the temperature dissipation is very fast and no punctual temperature increment can be observed in the motor frame. A similar conclusion is reached when analyzing the evolution of the average temperature in the motor nameplate (Fig. 7). A general increment is detected for the faulty motor, but no conclusive diagnostic can be obtained only relying on this fact.

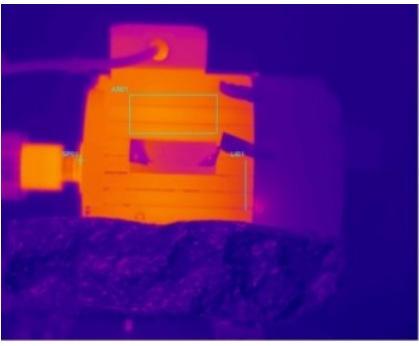

(a)

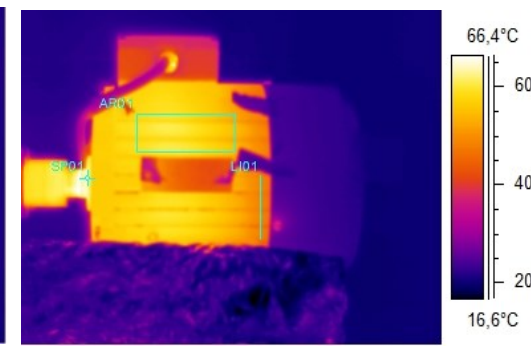

(b)
Fig. 6. Steady-state infrared thermograms for: (a) healthy motor and (b) motor with nine broken bars

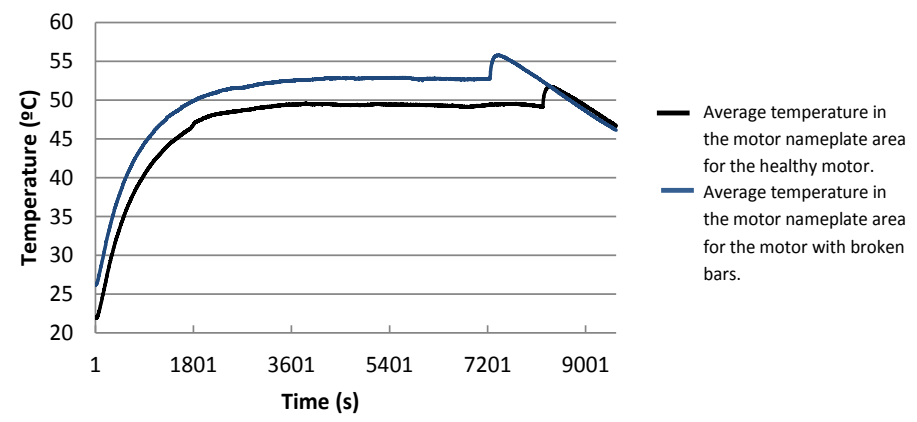

Fig 7. Temperature heating profiles for healthy motor (black) and motor with nine broken bars (blue)

\section{B. Bearing damages}

In practice, bearing damages are not easy to be detected by current analysis [39, 40], in spite of the fact that some authors have proposed current-based techniques to such purpose [41]. For some types of bearing failures, the damage does not lead to an evident increment of specific frequencies. Moreover, even if specific components are amplified due to the fault, it is necessary to know constructive characteristics of the bearing to be aware of the specific frequencies to be studied.

With regards to the analysis of transient currents, some recent works have proven the potentiality of the continuous transforms for tracking the fault-related harmonics, even if they have low amplitudes [42]; the extension of these techniques to the case of bearing failures is being investigated. On the other hand, the application of tools as 
the HHT or DWT has proven to be difficult for the detection of components with similar nature as those introduced by this fault, a proven in previous works [4344].

In this context, infrared data may provide very interesting information to reach a diagnostic conclusion. A level of bearing damage was forced in the laboratory, by combining a bad lubrication with an artificial damage forced with a hammer. The machine was operating during some months until the bearing finally collapsed (i.e. until the eccentricity level caused by the failure was so high that the rotor and stator rubbed). Infrared images, captured during the tests, are rather revealing. As shown in Fig. 8, clear differences are observed versus those of the healthy machine. Moreover, a significant temperature increase is concentrated in the bearing element (see Fig. 9). This increase was already evident after the fault was forced. This temperature increment in the bearing region leads to a quite reliable infrared pattern (totally different from those appearing in other faults) that informs on the presence of an abnormality in that element. Logically, further work should be necessary to accurately determine the level of failure based on the temperature increase of that element, but at least thermography analysis can serve as an alarm to warn the maintenance staff about a possible failure of that element, so that they can adopt corresponding maintenance actions in enough advance.

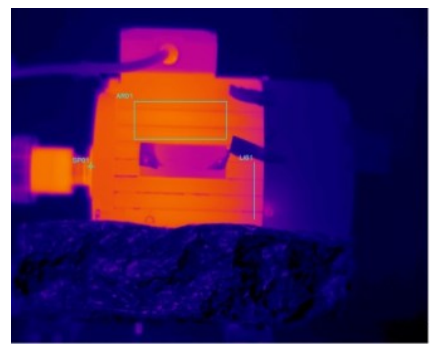

(a)

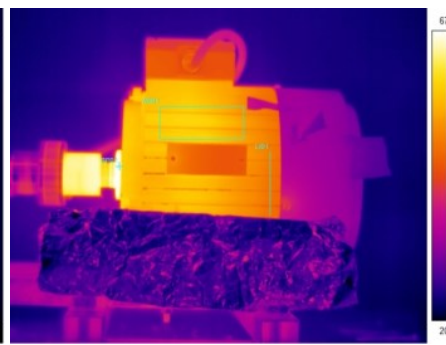

(b)
Fig.8. Steady-state infrared thermograms for: (a) healthy motor and (b) motor with damaged bearing

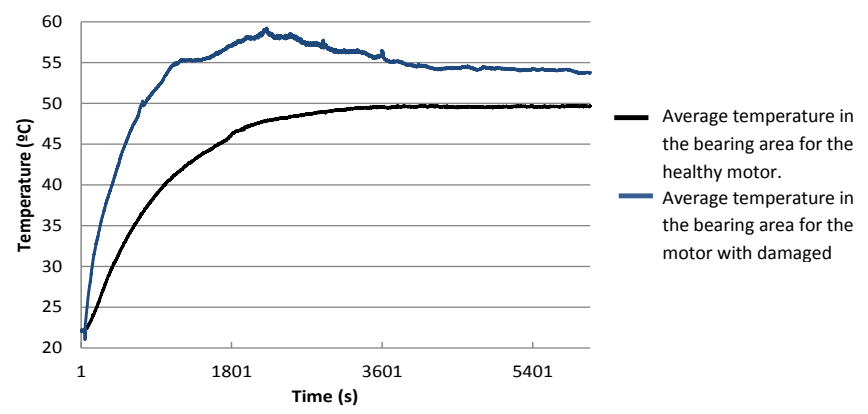

Fig 9. Temperature heating profiles for healthy motor (black) and motor with damaged bearing (blue).

\section{Cooling system problems}

Problems in the motor cooling system were simulated by inserting a cardboard in the internal part of the motor, so that the air penetration in the motor was obstructed (see Fig. 10). In real applications, this problem may be caused by the deposit of dust or dirtiness that obstructs the air input channels.

As for the previous tests, current and infrared data were captured since the motor was connected until the steadystate regime was well-established.
Obviously, neither MCSA nor advanced transient harmonic tracking are useful for the blocked input channel fault mode, since they will not lead to any fault indicating frequency.

On the other hand, infrared data reveals a generalized temperature increment in the motor (as it happened for broken bars), as observed in Fig. 11.

However, the temperature evolution profile is rather different if compared with that at the same point (motor nameplate) for the previous faults (Fig. 12). This specific profile could be indicative of the occurrence of this specific fault in the machine.

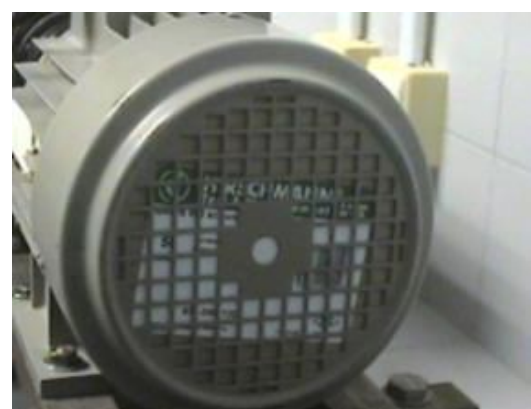

Fig. 10. Simulation of cooling system failure

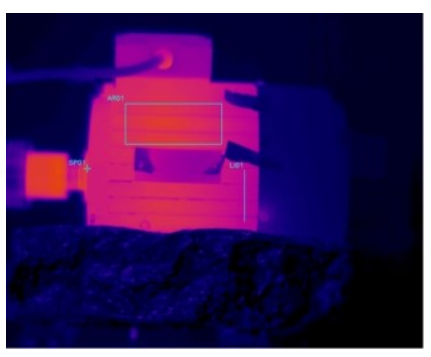

(a)

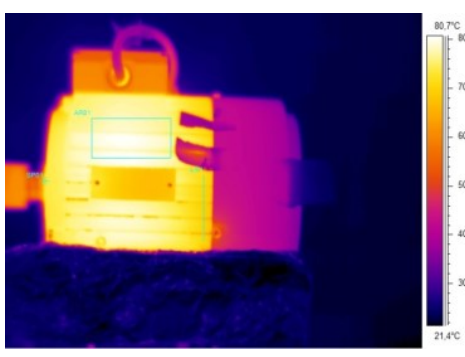

(b)
Fig.11. Steady-state infrared thermograms for: (a) healthy motor and b) motor with cooling system failure.

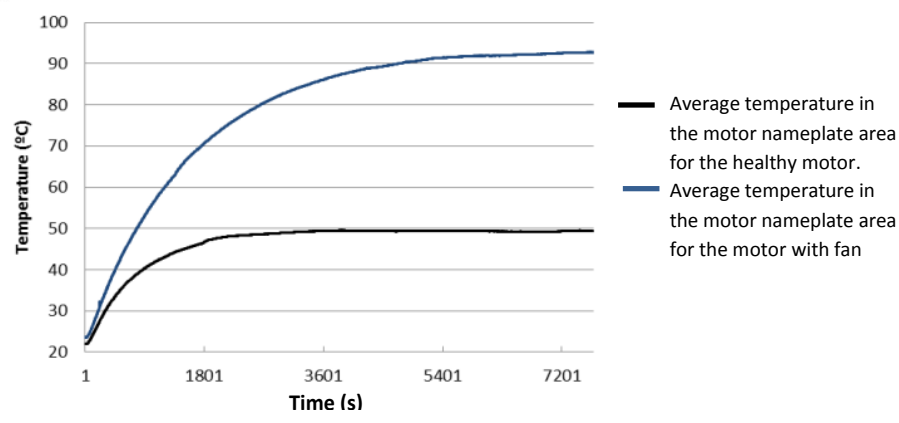

Fig 12. Temperature heating profiles for healthy motor (black) and motor with cooling system failure (blue).

\section{CONCLUSIONS}

A twofold approach combining the use of current and infrared data is proposed in the present work. The first stage of the approach relies on analyzing the registered current signals (both during transient and steady-state operation). Classical MCSA and Advanced Harmonic Tracking Analysis are combined in this stage in order to reach a diagnosis conclusion.

In the case that these techniques are not able to detect any fault or that they show discrepancies in their diagnostic results, infrared data are used in a second stage. In this second stage, qualitative analysis of thermography images can be used to either to discard or to ratify the presence of the failure in the machine. In general terms, it can be said 
that, as expected, the infrared technique is more sensitive to faults located near the machine frame surface rather than to internal failures.

On the other hand, the study of the temperature profiles during the heating process at different points of the machine frame can provide very useful information to determine the type of failure that is present. In this case, the only limitation is the length of the required data due to the long duration of the heating transient.

The proposed approach relying on non-invasive monitoring of the machine, can be especially useful in the case of large, critical motors in which the occurrence of eventual false positives/negatives may lead to severe repercussions in terms of economic losses or production shutdowns. For these motors, the implementation cost of the approach is far compensated by the higher reliability in the diagnostic.

\section{REFERENCES}

[1] W.T. Thomson, M. Fenger, "Current signature analysis to detect induction motor faults" IEEE Industry Applications Magazine, July/August 2001, pp. 26-34

[2] C. Yang, T-J. Kang, D. Hyun, S. Lee, J. Antonino-Daviu, J. PonsLlinares, "Reliable Detection of Induction Motor Rotor Faults Under the Rotor Axial Air Duct Influence," IEEE Transactions on Industry Applications, vol. 50, no. 4, pp 2493-2502, Jul/Aug 2014

[3] N.M. Elkasabgy, A.R. Eastham, G.E. Dawson, "Detection of broken rotor bars in the cage rotor on an induction machine" IEEE Transactions on Industry Applications, Vol. 28, No. 1, January/February 1992, pp 165-171

[4] F. Filippetti, G. Franceschini, C. Tassoni, P. Vas, "Recent developments of induction motor drives fault diagnosis using AI techniques“, IEEE Transactions on Industrial Electronics, Vol. 47, No. 5, October 2000, pp 994-1004.

[5] P. Zhang, Y. Du, T.G. Habetler, and B. Lu, "A Survey of Condition Monitoring and Protection Methods for Medium-Voltage Induction Motors," IEEE Transactions on Industry Applications, vol.47, no.1, pp.34,46, Jan.-Feb. 2011.

[6] J. R. Cameron, W. T. Thomson, A. B. Dow, "Vibration and current monitoring for detecting airgap eccentricity in large induction motors", IEE Proceedings, Vol. 133, Pt. B, No. 3, May 1986, pp. 155-163

[7] A. Bellini, C. Concari, G. Franchescini, C. Tassoni, A. Toscani, "Vibrations, currents and stray flux signals to asses induction motors rotor conditions." IEEE Industrial Electronics, IECON 2006 - 32nd Annual Conference on, 2006 , pp. 4963 - 4968

[8] S.M.J. Rastegar Fatemi, H. Henao, G.-A. Capolino, "The Effect of the Mechanical Behavior on the Stray Flux in an Induction Machine Based Electromechanical System," IEEE International Symposium on Diagnostics for Electric Machines, Power Electronics and Drives, 2007. SDEMPED 2007. , pp.155,160, 6-8 Sept. 2007.

[9] A. Khezzar, M. El Kamel Oumaamar, M. Hadjami, M. Boucherma, H. Razik, "Induction Motor Diagnosis Using Line Neutral Voltage Signatures," IEEE Transactions on Industrial Electronics, vol.56, no. 11, pp.4581,4591, Nov. 2009.

[10] S. M A, Cruz, "An Active-Reactive Power Method for the Diagnosis of Rotor Faults in Three-Phase Induction Motors Operating Under Time-Varying Load Conditions," IEEE Transactions on Energy Conversion, vol.27, no.1, pp.71,84, March 2012.

[11] R.R. Schoen and T.G. Habetler. "Evaluation and Implementation of a System to Eliminate Arbitrary Load Effects in Current-Based Monitoring of Induction Machines," IEEE Trans. Ind. Appl., Vol.33, No. 6, November/December 1997, pp. 1571-1577.

[12] J. A. Antonino-Daviu, M. Riera-Guasp, J. R. Folch, and M. Pilar Molina Palomares, "Validation of a new method for the diagnosis of rotor bar failures via wavelet transform in industrial induction machines," IEEE Trans. Ind. Appl., vol. 42, pp. 990-996, 2006.

[13] S. Lee, J. Hong, S.B. Lee, E. Wiedenbrug, M. Teska, and H. Kim, "Evaluation of the influence of rotor axial air duct design on condition monitoring of induction motors," IEEE Trans. on Ind. Appl., vol. 49, no. 5, pp. 2024-2033, Sept./Oct. 2013.

[14] J. Park, B. Kim, J. Yang, K. Lee, S.B. Lee, E.J. Wiedenbrug, M. Teska, and S. Han, "Evaluation of the Detectability of Broken Rotor Bars for Double Squirrel Cage Rotor Induction Motors," Proc. of IEEE ECCE, pp. 2493-2500, Sept. 2010.
[15] M. Riera-Guasp, J. A. Antonino-Daviu, M. Pineda-Sanchez, R. Puche-Panadero, and J. Perez-Cruz, "A General Approach for the Transient Detection of Slip-Dependent Fault Components Based on the Discrete Wavelet Transform," IEEE Trans. Ind. Electron., vol. 55, pp. 4167-4180, 2008.

[16] J. Pons-Llinares, V. Climente-Alarcón, F. Vedreño-Santos, J. Antonino-Daviu, and M. Riera-Guasp, "Electric Machines Diagnosis Techniques via Transient Current Analysis, " in Proceedings of the 38th Annual Conference of the IEEE Industrial Electronics Society, IECON 2012, 25-28 October, 2012, Montreal, Canada.

[17] J.A. Antonino-Daviu, M. Riera-Guasp, J. Pons-Llinares, J. RogerFolch, R.B. Perez, R.B. and C. Charlton-Perez, "Toward Condition Monitoring of Damper Windings in Synchronous Motors via EMD Analysis," IEEE Transactions on Energy Conversion, vol.27, no.2, pp.432,439, June 2012

[18] B. Li, X. Zhu, S. Zhao and W. Niu, "HV Power Equipment Diagnosis Based on Infrared Imaging Analyzing," International Conference on Power System Technology, 2006.

[19] Y. Chou and L. Yao, "Automatic Diagnosis System of Electrical Equipment using Infrared Thermography," International Conference of Soft Computing and Pattern Recognition, 2009.

[20] Y. Han and Y.H. Song, "Condition Monitoring Techniques for Electrical Equipment," IEEE Transactions on Power Delivery, vol. 18 , no. 1 , January 2003.

[21] J. Piotrowski, "Shaft Alignment Handbook", 3 ${ }^{\text {rd }}$. Edition, CRC Press, Taylor \& Francis, Boca Raton, 2007.

[22] S. U. Haq and T. Bashir, "Evaluation of Induction Motor Groundwall Insulation using Infrared Thermography," 2nd International Conference on Emerging Technologies Peshawar, Pakistan, 13-14 November 2006.

[23] J.Yun, K.Lee, J. Yoo, L.W. Lee, S.B. Lee, J. Yun, "Detection and Classification of Stator Turn Faults and High- Resistance Electrical Connections for Induction Machines" IEEE Transactions on Industry Applications, vol. 45, no. 2, Apr. 2009.

[24] Boglietti, A. Cavagnino, D. Staton, M.Shanel, M.Mueller, and C. Mejuto, "Evolution and modern approaches Thermal Analysis of Electrical Machines," IEEE Transactions on Industrial Electronics, vol.56, n.3, 2009.

[25] L. Frosini, A. Borin, L. Girometta, and G. Venchi, "A novel approach to detect short circuits in low voltage induction motor by stray flux measurement," in Proc. IEEE ICEM, Marseille, France, 2012, pp. 1538-1544.

[26] C. Harlișca, L. Szabó, L. Frosini, and A. Albini, "Bearing faults detection in induction machines based on statistical processing of the stray fluxes measurements," in Proc. IEEE SDEMPED, Valencia, Spain, 2013, pp. 371-376.

[27] D.G. Dorrell, W.T. Thomson, and S. Roach, "Analysis of airgap flux, current, and vibration signals as a function of the combination of static and dynamic airgap eccentricity in 3-phase induction motors," IEEE Trans. Ind. Appl., vol. 33, no. 1, Jan.-Feb. 1997, pp. 24-34.

[28] G. Salles, F. Filippetti, C. Tassoni, G. Grellet, and G. Franceschini, "Monitoring of induction motor load by neural network techniques," IEEE Trans. Power Electron., vol. 15, no. 4, Jul. 2000, pp. 762-768.

[29] H. Henao, C. Demian, and G.-A. Capolino, "A frequency-domain detection of stator winding faults in induction machines using an external flux sensor," IEEE Trans. Ind. Appl., vol. 39, no. 5, pp. 1272-1279, Sep./Oct. 2003.

[30] H. Henao, C. Demian and G.-A. Capolino, "A frequency-domain detection of stator winding faults in induction machines using an external flux sensor," in Conf. Rec. 37th IEEE IAS Annual Meeting, 2002, vol. 3, pp. 1511-1516

[31] H. Henao, G.-A. Capolino, and C. S. Martis, "On the stray flux analysis for the detection of the three-phase induction machine faults," in Conf. Rec. 38th IEEE IAS Annual Meeting, 2003, vol. 2, pp. 1368-1373.

[32] L. Frosini, A. Borin, A. Albini, and F. Benzi, "New techniques to simulate and diagnose stator winding faults in low voltage induction motors", in Proc. ICEM 2012, pp. 1781-1787.

[33] L. Frosini, E. Bassi, and L. Girometta, "Detection of stator short circuits in inverter-fed induction motors", in Proc. IECON 2012, pp. 5084-5089.

[34] R.A. Leonhard, and W.T. Thompson, "Vibration and stray flux monitoring for unbalanced supply and inter-turn winding fault diagnosis in induction machines," British Journal of Nondestructive Testing, pp. 211-215, July 1986.

[35] S. Shin, J. Kim, S.B. Lee, C. Lim, E. Wiedenbrug, "Evaluation of the influence of rotor magnetic anisotropy on condition monitoring of 2 pole induction motors," in proc. of the IEEE ECCE, pp. 638645, Sept. 2014. 
[36] J. Antonino-Daviu, M. Riera-Guasp, J. Pons-Llinares, Jongbin Park, Sang Bin Lee, Jiyoon Yoo and C. Kral, "Detection of Broken OuterCage Bars for Double-Cage Induction Motors Under the Startup Transient," IEEE Transactions on Industry Applications, vol.48, no.5, pp.1539,1548, Sept.-Oct. 2012

[37] M. Riera-Guasp, J. Pons-Llinares, F. Vedreno-Santos, J.A. Antonino-Daviu, M. Fernandez Cabanas, "Evaluation of the amplitudes of high-order fault related components in double bar faults," in proc. of the 8th IEEE International Symposium on Diagnostics for Electric Machines, Power Electronics and Drives, SDEMPED 2011, Bologna, Italy, September 2011.

[38] A. Bellini, F, Filippetti, G. Franceschini, C. Tassoni, R. Pasaglia, M. Saottini, G. Tontini, M. Giovannini and A. Rossi, "On-field experience with online diagnosis of large induction motors cage failures using MCSA", IEEE Trans. Ind. Appl., vol. 38, no. 4, pp. 1045-1053, Jul./Aug. 2002.

[39] H. Henao, G-A. Capolino, M. Fernández-Cabanas, F. Filippetti, C. Bruzzese, E. Strangas, R. Pusca, J. Estima, M. Riera-Guasp, and S.H. Kia, "Trends in Fault Diagnosis for Electrical Machines," IEEE Industrial Electronics Magazine, June 2014, pp. 31-42.

[40] F. Immovilli, A. Bellini, R. Rubini, and C. Tassoni, "Diagnosis of bearing faults in induction ma- chines by vibration or current signals: A critical comparison," IEEE Trans. Ind. Applicat., vol. 46, no. 4, pp. 1350-1359, July/Aug. 2010.

[41] R.R. Schoen, T.G. Habetler, F. Kamran, R.G. Bartfield, "Motor bearing damage detection using stator current monitoring", IEEE Trans. Ind. Appl., vol. 31, no. 6, Nov./Dec. 1995 , pp. 1274-1279.

[42] J. Pons-Llinares, J. Antonino-Daviu, J. Roger-Folch, D. MoríñigoSotelo, O. Duque-Pérez, "Mixed eccentricity diagnosis in InverterFed Induction Motors via the Adaptive Slope Transform of transient stator currents," Mechanical Systems and Signal Processing, vol. 48, no.1-2, pp. 426-435, Oct. 2014.

[43] J. Antonino-Daviu, P. Jover Rodriguez, M. Riera-Guasp, A. Arkkio, J. Roger-Folch, R.B. Pérez, "Feature Extraction for the Prognosis of Electromechanical Faults in Asynchronous Motors using the HilbertHuang Transform" Energy Conversion and Management, Elsevier, vol. 50, no. 7, pp. 1810-1820, July 2009.

[44] Z.K. Peng, P.W. Tse, F.L. Chu, "A Comparison Study of Improved Hilbert-Huang Transform and Wavelet Transform: Application to Fault Diagnosis for Rolling Bearing", Mechanical Systems and Signal Processing, Elsevier, Vol. 19, 2005, pp. 974-988.

\section{BIOGRAPHIES}

María J. Picazo received the M.Sc. degree in Electrical Engineering from the Universidad Alfonso X el Sabio of Madrid in 2003 and a Master degree in Maintenance Engineering in 2008 from the Polytechnic University of Valencia, Spain She is currently performing her Ph. D. Degree Studies in "Thermographic techniques as a predictive tool to diagnostic failures in electrical equipments" in the Electric Machines Department of the Polytechnic University of Valencia. She has been certified with Level 1 in Infrared Thermography by Infrared Training
Center (ITC) and in Maintenance Engineering Management by the Spanish Maintenance Society (AEM)

Professionally, she is in charge of the Maintenance Department in the Hospital Clinic of Valencia.

Jose Antonino-Daviu (S'04/M'08/SM'12) received his M.S. and Ph. D. degrees in Electrical Engineering, both from the Universitat Politècnica de València, in 2000 and 2006, respectively. He was working for IBM during 2 years, being involved in several international projects. Currently, he is Associate Professor in the Department of Electrical Engineering of the mentioned University, where he develops his docent and research work. He has been invited professor in Helsinki University of Technology (Finland) in 2005 and 2007 and in Michigan State University (USA) in 2010. He has over 60 publications between international journals, conferences and books.

His primary research interests are condition monitoring of electric machines, wavelet theory and its application to fault diagnosis and design and optimization of electrical installations and systems.

Vicente Climente-Alarcon (M'12) received his M.Sc. degrees in Chemical and Industrial Engineering in 2000 and 2011, and his Ph.D degree in Electrical Engineering in 2012, all from the Universitat Politècnica de València (Spain)

$\mathrm{He}$ has worked as Assistant Professor in the School of Industrial Engineering of the mentioned university, on research tasks in the area of condition monitoring of electrical machines, and externally as a consultant in automation and management of power systems. Currently he is carrying out postdoctoral research at the Department of Electrical Engineering and Automation, Aalto University (formerly Helsinki University of Technology), Espoo, Finland.

Rafael Royo Pastor holds a $\mathrm{PhD}$ in Mechanical Industrial Engineering and is currently a Professor at the Instituto de Ingeniería Energética- Universidad Politécnica de Valencia (UPV) - Spain. He is a specialist in heat transfer, with two particular domains of applications: internal combustion engines and energy optimization. Rafael has authored several international papers on engines for SAE, some of them with the research department of Renault Spain which has been a leading partner of UPV since 1993. Rafael also manages the Energy Simulation Group of the Energy engineering institute, carrying applied research projects for important companies such as ACCIONA and ASSYCE. Since 2009, he has been teaching Energy Optimization of Industrial Installations, and New Energy Technologies for Buildings at the Master of Sustainable Development.

Finally, Rafael is a key partner for ITC, leading the pool of instructors in Spain, and educating operators in both Spain and Latin America. Furthermore, he is not only an ITC level 3 certified operator, but also an active co-developer of ITC training programs.

Ariel Mota Villar received the B.S. degree in Electromechanica Engineering from the Universidad Central del Este, Republica Dominicana, in 2010, and a Master degree in Maintenance Engineering in 2013 from the Universitat Politecnica de Valencia, Spain. 